\title{
LA REFUTACIÓN DEL ORIGENISMO EN EL AMBIGUUM 7 DE MÁXIMO EL CONFESOR
}

\author{
Miguel Escobar Torres \\ Lcdo. Filosofía
}

\section{RESUMEN / ABSTRACT}

El artículo estudia la refutación del origenismo evagriano que lleva a cabo Máximo el Confesor en el Ambiguum 7, donde esta crítica está tematizada con mayor claridad. Máximo invierte la tríada origenista estabilidad-movimiento-creación, defendiendo con ello que las almas no preexisten a la creación, sino que lo que precede es la voluntad de Dios para con los seres creados, y que el cuerpo y el alma fueron creados simultáneamente.

This article studies the refutation of evagrian origenism that made Maximos the Confessor in the Ambiguum 7, where this critic is developed with more clarity. Maximos reverses the origenist triad formed by the concepts 'rest', 'motion' and 'creation', maintaining that the souls do not preexist the creation, but it was the God's will of each being that preexist before the creation, and that the soul and the body were created at the same time in the beginning.

\section{ORÍGENES Y EL ORIGENISMO}

Orígenes de Alejandría es un autor del siglo III, el filósofo más prolifico del cristianismo naciente. Se le considera uno de los tres grandes padres de la Iglesia, junto a Agustín de Hipona y Gregorio de Nacianzo. Es necesario apuntar dos aspectos respecto del alejandrino: en primer lugar, es un filósofo con una ambición 
intelectual tal que intentó abarcar cuantas cuestiones pudo en una época tan temprana de la cristiandad que pudo exceder los limites doctrinales, aún muy difusos. Sin embargo, hay que entender a Orígenes, no como a un autor que ha sobrepasado los limites de la ortodoxia, sino más bien como a un pensador genial que puso las bases de muchos debates teológicos posteriores. Apuntó, en algunos casos sin llegar a afirmarlas, algunas teorias que posteriormente fueron condenadas, como la apocatástasis y el subordinacionismo. El segundo aspecto es que, debido a la sombra de herejía que recayó sobre él a causa de estas teorías, una parte importante de su obra no nos ha llegado en el original griego, lo cual dificulta especialmente su estudio. Y no solamente a nosotros, sino ya en el siglo VII a Máximo el Confesor, quien probablemente leyó algunos florilegios de la doctrina ascética y espiritual de Orígenes, pero no su obra teológica, la cual le llegó sesgada por las tesis origenistas condenadas en el concilio de Constantinopla del año $543^{1}$.

La obra de Orígenes constituye la base filosófica y teológica sobre la cual se edificarian fundamentalmente dos corrientes: la ortodoxa, personificada en Basilio de Cesarea, Gregorio de Nacianzo y Gregorio de Nisa, y la heterodoxa, que va desde Eusebio de Cesarea y Arrio de Alejandría hasta Evagrio Póntico. A pesar de ser también el padre de la corriente ortodoxa, pronto el nombre de Orígenes se va a asociar a algunos autores que llevaron sus tesis al extremo, constituyendo herejías recogidas bajo el nombre genérico de "origenismo". El Orígenes que llega a Máximo el Confesor es el del origenismo evagriano, es decir, las tesis de la filosofia origeniana tal y como fueron interpretadas por el filósofo Evagrio Póntico, un autor considerado como uno de los Padres del desierto, y sus discípulos. Evagrio Póntico, aparte de ser famoso por su escrito sobre los ocho pecados capitales, es también el impulsor de la

\footnotetext{
Respecto de la recepción de la obra directa de Orígenes por parte de Máximo el Confesor, señala L. Manca: "Il Confessore avrebbe conosciuto Origene anzitutto attraverso le tesi condannate da Giustiniano (543), ma non si esclude che vi sia stata anche una conoscenza diretta, almeno di alcuni scritti, sopratutto del $D e$ Principiis. Il nome di Origene ricorre una sola volta in tutta l'opera massimiana." (MANCA, L., Il primato della volontà in Agostino e Massimo il Confessore, Armando Editore, Roma, 2002, p. 135). El nombre de Orígenes, como señala L. Manca, tan sólo lo menciona Máximo en PG 90, $120 B$.
} 
disciplina ascética que caracteriza a la espiritualidad monástica del cristianismo oriental, que pasó de generación en generación a través de colecciones de textos que, en el siglo XVIII, se agruparon en la Filocalía de la Oración de Jesús. Evagrio recupera categorias origenianas para elaborar su filosofia: por un lado recoge la triada acción-contemplación-deificación ( $\pi \varrho \alpha ́ \xi ı \zeta-\theta \varepsilon \omega \varrho i ́ \alpha-\theta \varepsilon \omega ́ \sigma ı \varsigma)$ para su doctrina espiritual, y por otro la triada estabilidad-movimiento-


estudiar en este artículo.

\section{EL ORIGENISMO BAJO LOS COMENTARIOS A LA OBRA DE GREGORIO NACIANCENO}

Las tesis de Orígenes llevadas al extremo, que vinieron a conocerse como origenismo, fueron condenadas en el Concilio de Constantinopla del año 543, pero los origenistas no cejaron en su empeño doctrinal y continuaron existiendo debates en los siglos venideros. Sin embargo, ya no podian usar como autoridad el nombre de un Orígenes sobre cuya obra se ceñía una pesada sombra de herejía. Tuvieron que buscar otro autor que gozara de reconocida fama y de cuyas obras se pudieran extraer pasajes que pareciesen refrendar sus posiciones. No fue dificil encontrar en Gregorio de Nacianzo a la figura ideal para sus ambiciones, y esto fundamentalmente por dos motivos: 1) su obra estaba escrita con un lenguaje poético y era dada al simbolismo, de manera que muchos de sus pasajes podían resultar ambiguos o, al menos, eran susceptibles de diversas interpretaciones; y 2) gozaba de una autoridad indiscutible que se fue forjando a partir de su muerte y más concretamente a partir del Concilio de Calcedonia del año 451.

2 Según escribe Luigi Manca, "Per Refoulé, Evagrio é più origenista dallo stesso Origene; per altri avrebbe correto Origene." (MANCA, L., Il primato della volontà in Agostino e Massimo il Confessore, Armando Editore, Roma, 2002, p. 133). El artículo del autor al que se refiere es REFOULÉ, F., "Evagre fut-il origéniste?", en Revue des Sciences philosophiques et théologiques, 47, 1963, pp. 398-402. Más adelante, Manca señala que es común considerar que "Evagrio rappresenta la radicalizzazione delle tesi origeniste, il cui influsso sul monachesimo orientale è stato enorme fino al tempo di S. Massimo" (Ídem). 
La fama de Gregorio el Teólogo (que así fue llamado después del Concilio de Calcedonia) llegó a ser tal, que sus escritos fueron considerados textos revelados, casi tan sagrados como los mismos textos bíblicos. En el mundo bizantino era el autor más citado después de la Biblia, y pronto se formó una tradición de autores que realizaban comentarios a sus discursos y oraciones. En esta corriente de comentadores se inscribe Máximo el Confesor, que emprende la explicación de diversos pasajes ambiguos o necesitados de interpretación de la obra del Nacianceno y del Pseudo-Dionisio Areopagita (entonces menos conocido y considerado el obispo del siglo I que fue convertido por San Pablo en el Areópago de Atenas) a petición de dos monjes, Juan de Cicico y un cierto Tomás. El resultado es el conjunto de escritos más conocido de Máximo el Confesor, los Ambigua ad Johannem y los Ambigua ad Thomam. En cualquier caso, en esta serie de escritos, cuyo fin es dilucidar el pensamiento verdadero de Gregorio el Teólogo respecto de algunas cuestiones que en su obra parecen dificiles de interpretar, está plasmada la consideración que san Máximo tenía del santo en cuestión. Por ejemplo, en el Ambiguum 19, en el punto 2, escribe san Máximo a su correspondiente Juan:

Nuestro padre bendito San Gregorio, siendo plenamente purificado por la filosofia práctica de todo lo que habitualmente desvirtúa la naturaleza humana, y con su intelecto rigurosamente imbuido por las cualidades del Espíritu Santo la causa de su dedicación a la contemplación divina), a través de su verdadera iniciación en el conocimiento verdadero, experimentando las mismas cosas que los sagrados profetas, y con estas palabras él enumera para nosotros las diferentes formas de profecía. ${ }^{3}$

Y no está de más reproducir un pasaje del Prólogo a los Ambigua ad Thomam referente a la autoridad de que gozaba el Nacianceno en aquel tiempo entre los autores cristianos de Bizancio:

3 Amb 19.2. También manifiesta su admiración hacia el venerado teólogo en otros pasajes: "Viendo la inmensa sabiduría que Dios dio a este sagrado y gran maestro de la verdad..." (Amb 21.1); "Siendo completamente inspirado por la Palabra, el gran maestro..." (Amb 32.2). 
Estas cosas pertenecen a ciertos pasajes en los escritos de Dionisio $y$ Gregorio, estos altamente elogiados $y$ benditos $y$ verdaderos hombres elegidos, quienes desde el principio fueron escogidos por Dios de acuerdo con su divino propósito. Ellos recibieron dentro de sí mismos la efusión de la sabiduria, que verdaderamente puede ser alcanzada por los santos, y dejando de lado una vida conforme a la naturaleza se ocuparon de la substancia del alma y abrazaron al Cristo único y viviente, quien -para decir algo de aún mayor grandeza- llegó a ser el alma de sus almas, manifestándose a través de todos sus actos, palabras y pensamientos, con lo cual uno está convencido de que los pasajes citados más adelante tuvieron de autor no a ellos, sino a Cristo, quien por la gracia se cambió por ellos. ${ }^{4}$

\section{LA DOCTRINA ORIGENISTA}

El origenismo evagriano, al que se dirige Máximo el Confesor, presenta varias tesis controvertidas a los ojos de los guardianes de la ortodoxia, personificada en los Padres Capadocios en Bizancio. La tesis origenista que con mayor ahínco combatirá Máximo es la de la preexistencia de las almas en Dios, aunque también está en juego la doctrina de la apocatástasis en la crítica desarrollada en el Ambiguum 7, como veremos.

En concreto, tal y como fue desarrollada por Evagrio Póntico y sus discipulos, la teoría gira en torno a tres conceptos: estabilidad


detrás del otro en este mismo orden ${ }^{5}$. En el principio existía una estabilidad original de las almas en la plenitud de Dios, en la que una multiplicidad de almas idénticas, libres y racionales se agrupaban bajo la unidad divina. En otras palabras, en el comienzo era el reposo de unas almas sin distinción de naturalezas y coexistentes con Dios. Los origenistas, a los que Máximo se refiere despectivamente con el apelativo de "Helenos" ('E $\lambda \lambda \eta \nu \iota x o ́ \varsigma)$ con el que en esa época se designaba

Ambiguum, "Prólogo", Pár. 3.

5 Máximo describe brevemente la teoría origenista con estas palabras: "De acuerdo con la opinión de estas personas (los Helenos), al comienzo existía una unidad de seres racionales, en virtud de la cual éramos connaturales con Dios, en cuyo seno teníamos nuestro sostén y nuestra casa. Además de esto, ellos hablaban de un movimiento que vino luego, como resultado del cual los seres racionales fueron dispersados distintamente, llevando a Dios a contemplar la creación de este mundo corporal, de manera que pudiera encerrarlos en cuerpos como castigo por sus pecados.” (7.2). 
a los paganos, citan un pasaje de Gregorio Nacianceno en el que el venerado teólogo señala, de pasada, que los hombres somos "partes

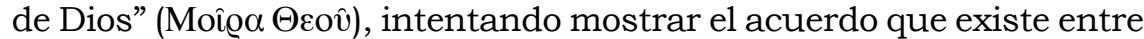
su pensamiento y la teoría origenista de la preexistencia de las almas. En la misma cita, el Teólogo añade que estas partes de Dios "cayeron de lo alto", lo que es entendido por los origenistas como una alusión

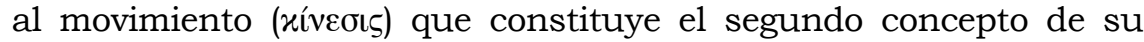
tríada metafísica. Según los origenistas, en la estabilidad original se produce una especie de hartazgo o aburrimiento (xó@os) que conduce a las almas a alejarse de Dios por su libre decisión. El movimiento es, por tanto, ontológicamente negativo, de alejamiento respecto del ser original. En otras palabras, el movimiento es el pecado, la caída de los seres racionales. Entonces, Dios reacciona creando el mundo ( $\gamma \varepsilon ́ v \varepsilon \sigma ı \varsigma)$, de modo que la creación no es querida en sí misma por Dios, sino que es respuesta a la acción pecaminosa de las almas preexistentes. Dios las encierra en distintas naturalezas y en los límites de la corporalidad, que dificultará en mayor o menor medida el ejercicio de su racionalidad en función de su grado de alejamiento de Dios. El objetivo de Dios es enseñarle el camino de retorno a la estabilidad originaria a través de las penas de un mundo alejado de Él, siendo éste entendido como lugar de expiación de culpas y el cuerpo como una prisión de la cual el alma debe ser despojada a través de una práctica ascética de purificación. Los origenistas arguyen que el Nacianceno se refería a este mismo movimiento de retorno cuando sostenia, al final del pasaje citado, que el hombre debe librar una batalla contra las pasiones para volver la vista a Dios.

La misión de Máximo es hacer ver que Gregorio en ningún momento suscribe la tesis de la preexistencia de las almas, ya que no explicita que la caída haya tenido lugar antes de la creación, $\mathrm{y}$, rechazando la interpretación origenista, proponer una nueva interpretación a la luz de la ortodoxia.

\section{LA REFUTACIÓN DE LA EXISTENCIA DE UNA ESTABILIDAD PREVIA A LA CREACIÓN}

Para refutar esta tesis origenista, que ya fue condenada en Constantinopla en el año 543, Máximo desarrolla tres argumentos muy lúcidos. En primer lugar, plantea que si aceptamos que 
efectivamente hubo una estabilidad original de las almas en la plenitud de Dios y, en un momento dado, estas almas se hartaron de dicha situación y cayeron a este mundo corporal del que tienen que liberarse, en el momento en que esta liberación suceda y sea efectivo el retorno a la estabilidad original, ¿qué garantiza que no se vuelvan a aburrir de nuevo, propiciando la reiteración de todo este proceso? ¿Hay alguna razón por la que este movimiento de expansión y contracción no se repita ad infinitum? ${ }^{6}$

A este interrogante san Máximo añade una posible objeción de los origenistas: la garantía de que esta repetición infinita no tenga lugar es la experiencia por la que pasan los seres caidos. Los seres, una vez que prueban las penas de una existencia lejos de Dios, preferirán la estabilidad original a la que retornan aunque ésta les provoque hastío. La respuesta de Máximo a esta posible objeción tiene que ver con la cuestión del carácter absoluto o relativo de Dios: si fuera cierta esta objeción, entonces Dios no sería deseable en sí mismo, sino en relación con la experiencia de lo opuesto. Si Dios aburre, pero es preferible a la experiencia de su opuesto, entonces Dios sería el "mal menor". Necesitaría de lo otro para ser deseado, lo cual, en palabras de Máximo, es blasfemia. Máximo entiende, junto a los Capadocios y Pseudo-Dionisio, que Dios es deseable de por sí, que es una plenitud rebosante que no puede ser atrapada bajo ningún concepto y que, por tanto, no puede ser controlada, con lo cual jamás podrá despertar aburrimiento. Éste es provocado por la sensación de control, mientras que Dios es lo único que escapa a nuestro control, y si creemos entenderlo (y, por ende, controlarlo), no es a Dios a quien estamos entendiendo sino a un ser distinto de Dios. En consecuencia, lo que los origenistas entienden por Dios no es Dios realmente, sino algo que se le parece, que es finito y que, en consecuencia, puede provocar hartazgo. Dios es, en conclusión,

6 “¿Qué prueba tienen de ello? Pues si esto que dicen fuera cierto, necesariamente se sigue que los seres racionales, cuando se encuentren en las mismas circunstancias, serán sometidos a los mismos cambios ad infinitum. Pues nadie que a través de la experiencia haya sido capaz al menos una vez de despreciar algo no encontrará razón para cesar de hacerlo por toda la eternidad. Y si los seres racionales han de ser arrastrados de este modo, y no han de tener esperanza alguna en un fundamento inamovible en la Belleza, ¿qué condición más miserable que éste podría ser posible?" (Ambiguum, 7.4). 
Aquél más allá del cual nada es deseable ni inimaginable.

En tercer lugar, Máximo desarrolla un argumento típicamente

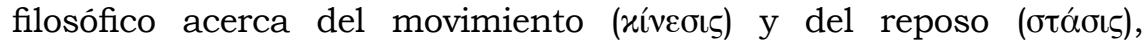

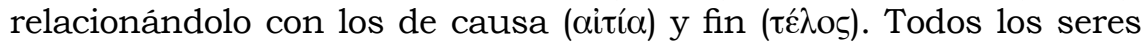
tienen causa y fin, y todos los seres tienden a su causa como fin, pues la causa y el fin son uno y lo mismo. La tesis de Máximo es, pues, que tan sólo está en reposo aquel ser que tiene en si su causa y su fin, y esto sólo se da en Dios. Los seres creados tienen su causa en Dios y, por tanto, también su propio fin. Dios es la causa y el fin de todos los seres creados, que, al ser Dios ontológicamente distinto a ellos, están siempre en un movimiento constante que tiende hacia Dios, ya sea con un movimiento sensible o intelectual. De este modo, Máximo arguye que los seres distintos de Dios, al tener su causa fuera de sí, no es posible que estén originalmente en reposo. Dios está en reposo porque Él es su causa y fin, pero los seres no hallaran el reposo hasta que no se unan a Dios, al que tienden por naturaleza.

\section{EN QUÉ SENTIDO INTERPRETA MÁXIMO QUE SOMOS "PARTES DE DIOS"}

En ningún momento niega Máximo que exista "algo" eterno en nosotros, "algo" que preexiste a la creación. La cuestión está en dilucidar qué cosa es este "algo" que hace que podamos ser interpretados como "partes de Dios", como hace Gregorio Nacianceno. He aquí una de las tesis más originales de Máximo, que será el punto de partida de su teoría de los $\lambda$ ó $\gamma_{0 \iota^{7}}$ : aquello en nosotros que preexiste a la creación no es nuestra realidad sustancial, sino la voluntad de Dios para con nosotros. El argumento que esgrime es como sigue: Dios crea el mundo mediante un acto de libre voluntad,

\footnotetext{
Es importante señalar aquí que usamos el término griego para evitar malas interpretaciones, ya que el término lógos es entendido habitualmente como razón, como discurso o racionalidad, mientras que el modo en que Máximo lo entiende es diferente, de manera que si lo traducimos por estas acepciones, no estamos entendiendo el mensaje de Máximo, pero si lo traducimos como lo entiende Máximo, se pierde el impacto que la palabra $\lambda$ ó ${ }^{\circ}$ s tiene para la filosofia griega en general y cristiana en particular, sobre todo sus resonancias joánicas que identifican al $\Lambda$ ó $\gamma$ os supremo con la segunda persona de la Trinidad.
} 
luego la voluntad de crear el mundo precede al acto de la creación, y la voluntad para con los seres creados precede a la voluntad del acto creador, de modo que la voluntad de los seres creados precede a los seres creados y es eterna. En otras palabras, somos queridos por Dios desde antes de ser creados. Nuestra existencia responde, por tanto, a la voluntad de Dios.

Máximo identifica la voluntad de Dios con el $\lambda$ ó $\gamma o s$, tesis muy propia de nuestro monje palestino. Con un argumento de autoridad, señala que Pseudo-Dionisio define los $\lambda$ ó $\gamma o$ como buenas voluntades (ä $\gamma \alpha \theta \alpha \theta \varepsilon \lambda \eta \dot{\mu} \mu \alpha \tau \alpha)$ de Dios. No obstante, fue Juan de Escitópolis, autor que media entre Pseudo-Dionisio y Máximo el Confesor, el que acuñó la expresión $\theta \varepsilon i ́ \alpha$ $\theta \varepsilon \lambda \eta j \mu \alpha \tau \alpha$ (divinas voluntades) para definir los $\lambda$ ó $\gamma$ ol. En cualquier caso, Máximo asume esta definición y la tematiza, elaborando una genial teoria que lo convierte en uno de los autores más originales de la Edad Media. Cada uno de los seres creados alberga en sí un $\lambda$ ó 0 os propio, dándose una doble relación: Cristo- $\Lambda$ ó $\gamma$ s está de esta forma presente en cada uno de los seres, y cada uno de los seres está asimismo en Cristo. Pues la multiplicidad de $\lambda$ ó $\gamma$ or correspondientes a todos los seres creados se

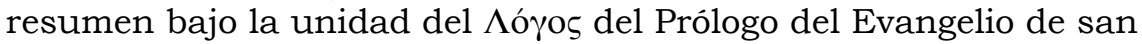
Juan $^{8}$. El $\lambda$ ó $\gamma$ os de cada ser, que constituye la presencia de Cristo en él, es la voluntad de Dios para con dicho ser, una voluntad que precede a su creación. En este sentido se dice que somos "partes de Dios".

Esta voluntad también es entendida en dos aspectos: por un lado como causa, ya que es la razón de su ser, y por otro como fin, ya que es el proyecto que Dios tiene para dicho ser. Pero si el ser

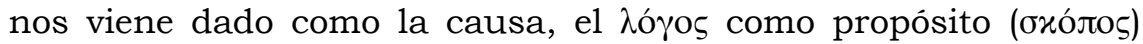
de nuestra existencia, debe ser llevado a cabo por cada uno de nosotros en el ejercicio de nuestra libertad y nuestras facultades vitales. La existencia humana es dinámica, está en proceso hacia el cumplimiento de su $\lambda$ ó $\gamma o \varsigma$, pero no en virtud de una

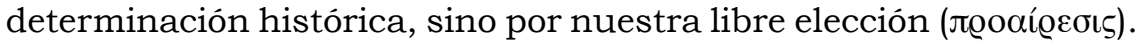
El $\lambda$ ó $\gamma$ os, entendido como propósito de nuestra existencia, a cuyo

8 Máximo enfatiza en el párrafo 7. 20 el carácter apofático del $\Lambda$ ó $\gamma$ os en relación con los seres creados. 
cumplimiento estamos llamados todos los seres racionales, es la

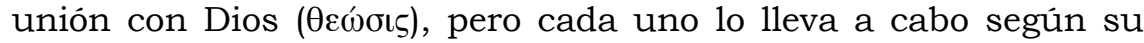

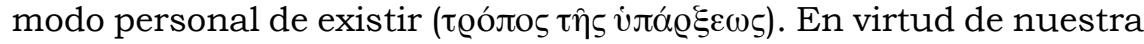
libre decisión, podemos estar más o menos cerca de la senda

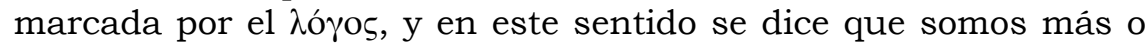
menos partes de Dios. No todos son Dios en la misma medida:

Él [un hombre santo] es "parte de Dios", por tanto, en la medida en

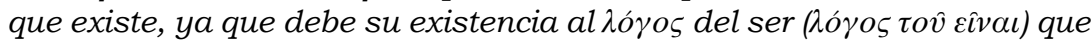
está en Dios; y es "parte de Dios" en la medida que es Bueno, ya que

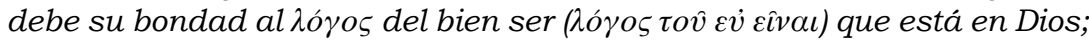
y es "parte de Dios" en la medida en que es Dios, debido al $\lambda o ́$ os de su

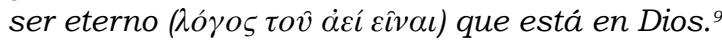

Hay, en consecuencia, diversos niveles de participación en Dios: el ser ( $\varepsilon \hat{\imath} v \alpha \iota)$ que nos viene ya dado por el acto creador de Dios; el ser-



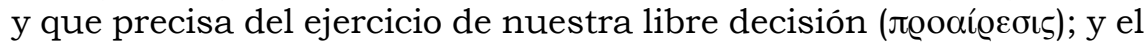

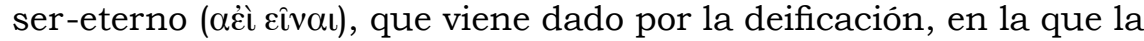



Es interesante observar cómo Máximo, llevado por el celo de la ortodoxia en su refutación de la tesis origenista de la preexistencia de las almas, desarrolla una teoría de corte existencial acerca del sentido de la existencia que seguirá presente en el resto de sus obras posteriores, tanto las más metafísicas (los Ambigua ${ }^{10}$ fundamentalmente) como las que trata de las dos voluntades en Cristo y tiene una orientación más cristológica y antropológica (en especial los Opuscula Theologica et Polemica ${ }^{11}$ ).

$9 \quad$ Amb 7.22.

10 En el Ambiguum 41, uno de los más conocidos del pensador bizantino, este carácter existencial está presente cuando expone que el propósito de la existencia humana consiste en superar las cinco polaridades del ser hasta alcanzar la deificación por la gracia. El carácter existencial de la filosofia maximiana impregna el resto de los Ambigua, ya sea explícitamente o a través de su estilo.

11 Maxime le Confesseur, Opuscules Théologiques et polémiques, Int. de J.-C. Larchet, trad. de Emmanuel Ponsoye, Les Éditions du Cerf, Paris, 1998. Es esta obra se dedica a refutar el monotelismo y el monoenergismo, nuevas variantes del pasado monofisismo, así como el nestorianismo, que, según él, aboca en última instancia al monofisismo. En estos escritos se centra en el acto de la decisión y el ejercicio de la libertad, sin perder el carácter existencial al que aludimos. 


\section{EL ALMA Y EL CUERPO SON CREADOS SIMULTÁNEAMENTE}

Tras haber explicado en qué sentido se dice que somos "partes de Dios", entendiendo que lo eterno en nosotros es la voluntad de Dios para con nosotros y no nuestra realidad sustancial, manteniendo así la radicalidad de la diferencia ontológica, Máximo sostiene que el cuerpo y el alma fueron creados simultáneamente, rechazando la tesis origenista de que el cuerpo fue creado como el lugar de expiación de las culpas de un alma que le precedía. Y Máximo no sólo sostiene la simultaneidad de la creación de cuerpo y alma, sino que además asevera que no los podemos concebir separados uno de otro. El alma existe en relación al cuerpo, y el cuerpo en relación al alma, y ninguna de los dos tendría sentido si no es considerado junto al otro. El hombre es, por tanto, un ser esencialmente compuesto.

Una de las consecuencias más significativas de esta tesis maximiana es que el cuerpo se convierte en una realidad querida por Dios en sí misma, y no tan sólo como respuesta al pecado de las almas, como mantenían los origenistas. De la tesis origenista de la preexistencia de las almas podemos extraer una concepción del hombre como ser escindido, atrapado en una naturaleza corporal que le es absolutamente ajena. Máximo, en cambio, lo entiende como un ser compuesto de alma y cuerpo, que se entrelazan e integran para formar la unidad de la persona. Por otro lado, este carácter compuesto del ser humano llevará a Máximo a entender al hombre como un crisol de la creación, que se halla entre dos polos: el intelectual y el sensible ${ }^{12}$, a cuya integración está llamado.

La otra gran consecuencia es de carácter soteriológico: como la corporalidad es querida por Dios, la deificación, fin al que todos los hombres estamos llamados desde antes de la comisión del pecado

12 Esto no está explícito en el Ambiguum 7, que es el que estamos estudiando en el presente artículo, sino en el Ambiguum 41, en el que divide el ser en cinco polaridades: 1) el ser creado y el ser increado, 2) el mundo intelectual y el mundo sensible, 3) el cielo y la tierra sensibles, 4) el paraíso y la tierra habitada, y 5) el ser femenino y el ser masculino. El hombre, en este esquema, se sitúa entre medio de todos, siendo portador de todas las polaridades e integrándolas en su ser. 
original, no excluye nuestra naturaleza corporal y la peculiaridad de nuestra persona. Máximo el Confesor se cuida siempre de no excluir del plan de salvación ninguna de las propiedades de la naturaleza humana, con el fin de que sea salvada la naturaleza humana sin menoscabo de ningún tipo, salvo el pecado, que no forma parte de ella. Así pues, tras la muerte, que es cuando tiene lugar de modo pleno la deificación final, el hombre no será un ser meramente inteligible, sino que seguirá manteniendo una suerte de forma corporal, aunque iluminada con la luz del espíritu.

La experiencia mística no excluye los elementos animicos propios de la naturaleza corporal, tales como la pasión (лcîбı), el


Caritate la experiencia mística como ójó $\theta \varepsilon \iota \alpha$ (ausencia de pasiones), ésta debe ser entendida como imperturbabilidad. Máximo describe el ascenso del hombre a Dios como un camino marcado por una cadena de decisiones libres por el bien, que lleva al hombre a potenciar la opción buena y palidecer la menos buena, lo cual aboca a la inmutabilidad del hombre, que ya no oscila entre opuestos al estar su senda perfectamente enderezada hacia el bien. Máximo asume que las pasiones son buenas en sí, ya que son naturales y, por tanto, creados por Dios, pero que se pueden desvirtuar debido al ejercicio del libre albedrio ${ }^{14}$ que desvia la voluntad gnómica ${ }^{15}$ hacia el no-ser en lugar de lo que realmente es. Esta postura contrasta

13 "Este estado, provocado por la contemplación de Dios y la experiencia de la ale-

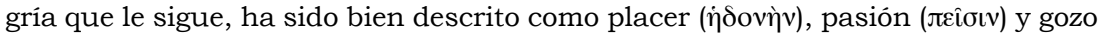



14 En este aspecto, la teoría de Máximo el Confesor guarda muchas semejanzas con la de Agustín de Hipona. Luigi Manca, partiendo de una insinuación de Urs von Balthasar, ha llevado a cabo un estudio de comparación de ambas teorías y una investigación de la posible recepción del africano en la obra del palestino.

15 Así traduzco $\gamma v \omega ́ \mu \eta$, si bien puede ser también traducido por disposición de ánimo (Larchet) o, sencillamente, voluntad reflexiva. En cualquier caso, Máximo se refiere a la voluntad que pertenece a la persona y que, por tanto, está relacionada

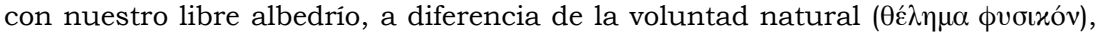
que constituye una propiedad de la naturaleza. La voluntad gnómica y la voluntad natural a veces pueden estar enfrentadas, ya que la voluntad natural tiende siempre hacia la conservación del ser y hacia el $\lambda$ ó $\gamma$ os de la naturaleza, mientras que la voluntad gnómica oscila entre contrarios, entre el ser y el no-ser, entre lo bueno y lo malo, etc., y puede en consencuencia desviarse hacia la destrucción de su propio ser. 
visiblemente con el marcado intelectualismo de Evagrio Póntico, que define la deificación como una experiencia exclusivamente intelectual ${ }^{16}$.

La mística de Máximo es, por consiguiente, una mística de la determinación personal, a diferencia de la mística de la disolución o absorción de la divinidad propia del origenismo evagriano. Para explicar cómo es posible la unión del hombre con su Creador en la experiencia mística, sin que queden menoscabadas de ningún modo la persona y la naturaleza humana, Máximo usa habitualmente la metáfora del hierro y del fuego. El hierro encendido, sin dejar de ser hierro, adquiere también la naturaleza del fuego. Puede, por tanto, cortar debido a la actividad que corresponde a la naturaleza del hierro, pero también puede quemar debido a la actividad que corresponde a la naturaleza del fuego. De este modo, el hierro y el fuego se hacen uno, sin que haya en esta unidad mezcla ni confusión, pues en un mismo acto podemos discernir la actividad de cortar y la actividad de quemar. Así sucede en la deificación, en la que el hombre se hace Dios sin perder su personalidad y manteniendo su naturaleza.

\section{CONCLUSIÓN}

En resumen, Máximo desarrolla su teoría metafísica a partir de su crítica a la doctrina origenista, que aún se mantenía viva en varios círculos monacales. No obstante, no desecha los términos del origenismo evagriano, sino que más bien los reconvierte a la ortodoxia. Debemos entender al monje palestino como un filósofo que convierte el origenismo a la ortodoxia, asumiendo sus conceptos.

De la crítica al origenismo surge su teoría de los $\lambda$ ó $\gamma o$, que podria ofrecer al hombre actual una filosofia de corte existencial, aunque los términos sean los habituales de los debates bizantinos.

16 En el artículo de Manuel Belda, "La preghiera continua secondo Massimo il Confessore", en Annales Theologici, n 2, vol. 26, 2012, pp. 305-322, es puesta de manifiesto esta diferencia entre la mística de Máximo el Confesor, que la entiende como una experiencia extática en la que el amor juega el papel principal, y la de Evagrio Póntico, para el cual la experiencia mística es puramente intelectual. 
La tesis según la cual Máximo el Confesor sería un autor poco original respecto a Orígenes y Evagrio no es válida hoy dia, cuando ya se han estudiado las obras maximianas y se ha puesto de manifiesto su originalidad ${ }^{17}$. Tal vez sea este aspecto de su doctrina el que convierte al monje palestino en un autor muy interesante y diferente en la Edad Media. Y es de la crítica al origenismo evagriano, desarrollada sobre todo en el Ambiguum 7 que hemos estudiado, de donde surge lo principal de su teoría.

\section{BIBLIOGRAFÍA}

- MAXIMOS THE CONFESSOR, On difficulties in the Church Fathers. The Ambigua, Edited and Translated by Nicholas Constas, Harvard University Press, Cambridge (Massachussets), London (England), 2014.

- BELDA, M., "La preghiera continua secondo Massimo il Confessore", en Annales Theologici, $\mathrm{n}^{\circ}$ 2, vol. 26, 2012, pp. 305-322.

- BALTHASAR, H. Urs von, Massimo il Confessore. Liturgia cosmica, Trad. De Luciano Tosti, Editoriale Jaca Book SpA, Milano, 2001.

- LARCHET, J.-C., "Introduction", en Saint Maxime le Confesseur, Ambigua, Col. L'Arbre de Jessé, Les éditions de l'Ancre, Paris Suresnes.

- MANCA, L., Il primato della volontà in Agostino e Massimo il Confessore, Armando Editore, Roma, 2002.

-SHERWOOD, P., The earlier Ambigua of Saint Maximus the Confessor and his refutation of Origenism, "Orbis Catholicus", Herder, Roma, 1955.

17 Urs von Balthasar, Luigi Manca, Manuel Belda, Lars Thunberg y Jean-Claude Larchet son algunos de los que han reivindicado la originalidad de Máximo el Confesor, elevándolo a la categoría de uno de los filósofos más notables y originales de toda la Edad Media. 